\title{
Evaluation of Antioxidant Potential and Efficacy of Terpenoid Rich Fraction of Phyllanthus Amarus (Schum and Thonn) Whole Plant in the Amelioration of High Salt Diet Induced Obesity.
}

Tope Israel Fasan ( $\nabla$ tifasan@pgschool.lautech.edu.ng )

Ladoke Akintola University of Technology Faculty of Basic Medical Sciences https://orcid.org/00000002-3738-4998

Olubukola Sinbad Olorunnisola

Ladoke Akintola University of Technology Faculty of Basic Medical Sciences

Adewale Adetutu

Ladoke Akintola University of Technology Faculty of Basic Medical Sciences

Bamidele Stephen Ajilore

Osun State University College of Health Sciences

\section{Research Article}

Keywords: High salt intake, Phyllanthus amarus (Schum. and Thonn), Terpenoid rich fraction, Antioxidant potential, Obesity

Posted Date: July 15th, 2021

DOl: https://doi.org/10.21203/rs.3.rs-562700/v1

License: (c) (i) This work is licensed under a Creative Commons Attribution 4.0 International License.

Read Full License 


\section{Abstract \\ Background}

It's overwhelmingly accounted that there is high prevalence of high salt diet related adiposity and metabolic antioxidant infringement worldwide. The present study thus aimed to establish the folkloric use of Phyllantus amarus by traditional practitioners and compliment orthodox medicine in the management of high salt diet driven adiposity and vehemently associated with pro-oxidant cascades. The principal focus was to fractionate, evaluate the lethal dose of terpenoid rich concentrate of the Phyllanthus amarus (Schum and Thonn) whole plant using up and down method and investigate the in vivo antioxidant potential and antiobesity of the rich concentrate in healthy adult male Sprague-Dawley rats fed with $8 \%$ high salt diet for 8 weeks.

\section{Results}

The results of the study revealed that there was a significant $(p<0.05)$ weight gained $(54.50 \%)$ in the experimental group fed with a high salt diet when compared with rats fed with normal chow $(51.19 \%)$. However, rats co-administered with High salt diet (8\%) and terpenoid rich fraction (TRF) of the whole plant $(75,100,150 \mathrm{mg} / \mathrm{kg} /$ body weight), had a significant weight recuperation in dose-dependent manner $(50.86 \%, 48.13 \%, 43.25 \%)$ in comparism to groups fed with normal rat chow $(51.19 \%)$, with corresponding significant $(p<0.05)$ and dose-dependent decrease in the concentration of oxidative marker product malondialdehyde (MDA) $(9.38 \pm 0.22,7.92 \pm 0.11,6.03 \pm 0.18)$ and dose-dependent metabolic improvement of both the non-enzymatic reduced Glutathione (GSH) $(40.15 \pm 0.04,46.21 \pm 0.01,51.22 \pm$ $0.03)$ and enzymatic catalase $(25.22 \pm 0.01,30.31 \pm 0.05,38.52 \pm 0.03)$ activities.

\section{Conclusion}

Therefore, the terpenoid rich fraction of Phyllanthus amarus (Schum and Thonn) whole plant could therefore be applied as a recuperative agent against obesity and prooxidant proliferation in high salt diet related pathologies.

\section{Background}

The human body is in continuous engagement preventing excess pro-oxidants, although beneficial to basic metabolism such as phagocytosis to a certain decree [1] and interested researchers have accounted that uncontrolled radical storming usually leads to pathological changes associated with aging [2]. Moreover, the pathological aetiologies as accounted have also been generally linked to gluttonous acts for ready-made meals, usually preserved or flavoured with high salt, which eventually leading to obesity [3]. The recommendation of table salt intake, majorly $40: 60$ by composition of Sodium/Chloride $(\mathrm{Na} / \mathrm{Cl})$, in the management of obesity and oxidative derailments [4] had received much 
attention over the past years [5]. It has been established that high salt diet intake is the major cause of obesity, stroke [6], an elevated number of circulating leukocytes and oxidative stress [7], nephrotoxicity and other health complicated morbidities [8]. Although, oxidative status plays a critical role in the maintenance of homeostasis and immune responses [9], however, uncontrolled proliferation of prooxidants, pathologically impairs intracellular integrity, resulting in cardiovascular disorders such as atherosclerosis and myocardial infarction [10]. Moreover, non-enzymatic glutathione depletion induced by high salt infringement in animal models has been accounted and correlatively linked to severe other morbidities such as hypertension and cardiac arrest [11].

Withal supplementation with three major classes of phytochemical antioxidants viz-a-viz terpenoids, phenolics, and alkaloids, have been reported to ameliorate some metabolic lesion, reduce blood pressure (BP) [12] and provide protection against oxidative cardiovascular injury [13]. Several studies have also reported that the levels of some non-enzymatic and enzymatic scavengers such as vitamin $E$ and superoxide dismutase, respectively, were downcasted in salt-induced hypertensive patients [14]. However, a range of antioxidant defences from galenicals, have evolved to detoxify reactive oxygen species, a major one of which is the reduced glutathione, potentiating as radicals' scavengers [15][16]).

Naturally, the antioxidant mechanism occurring in the human body has the potential in the maintenance of homeostasis, regulation of the prooxidant cascade and leptin hormone related obesity [6]. Nonetheless, exposure to a high salt diet infiltrated the production of excessive reactive oxygen species and its by-products, which are sometimes used as bioindicators/markers[17]. The possibility of terpenoid but exogenous phytoconstituent from easily available medicinal plants, perhaps acting also as free radical scavengers, quenchers of singlet oxygen, reducing agents and in ameliorating the high salt diet predisposed obesity is thus paramount in this study.

Terpene is a class of secondary metabolites which consists of five carbon isoprene per unit $\left(\mathrm{C}_{5} \mathrm{H}_{8}\right)$ and can be bonded into a complex form. The simplest example is myrcene or monoterpene. Terpenoids, a derivative of terpenes, are divided into monoterpenes, diterpenes, triterpenes, sesquiterpenes, and sesquiterpenes depending on the number of isoprene carbon units. Most of the terpenoids are biologically active against many diseases and commonly used as anticancer drugs, such as Taxol, while others are used as flavorants and nice fragrances [18]. Its potency is usually exhibited by the ability of the isoprene double bond [19], to actively scavenge the unstable macromolecules and shortchanged bonded metabolic radicals $[21,22]$.

Phyllantus amarus (Schum \& Thonn), (Fig. 1) a tropical annual but bitter herbal shrub [20], belonging to the Euphorbiaceae family. It's commonly known as Stonebreaker by the English speaking folk, Eyin Olobe by the Yoruba tribe and comprising of more than 600 species, of which are $P$. accuminatus, $P$. amarus, $P$. pulcher, $P$. niruroides, $P$. anisolobus, $P$. orbiculatus, $P$. emblica, $P$. flexuosus, $P$. raticulatus, $P$. fraternes, $P$. simplex, P. mullernus, P. urinaria, P. virgatus, P. niruri and $P$. watsonii [21]]. 
Phyllanthus amarus (Schum \& Thonn) is one of the important and acceptable medicinal plants, long world widely utilized in ethnomedicine. Its medicinal usage as antidiabetic and hypocholesterolemic [22], antioxidant, anti-cancer [23], anti-inflammatory [24], antihypertensive (28 and 29), and antimicrobial [25] had all been established. Others are hepatic and renal protective potentials in which the natural remedy is usually in the form of an infusion or decoction of the whole plant or its aerial parts [8]. This study thus evaluated the efficacious potential of the terpenoid rich fraction (TRF) of Phyllanthus amarus (Schum.and Thonn) whole plant in high salt diet-related oxidative stress and adiposity, which is nonexistent in the literature.

\section{Methods}

\subsection{Ethics approval and consent to participate}

The protocol of the study was approved by the university, Department of Biochemistry review board and ethical committee, without a reference number having conformed to the International guidelines of the National Institute of Health (NIH), (publication 85-23, 1985), for laboratory animal ethics.

\subsection{Plant preparation}

The harvested Phyllantus amarus (Schum. \& Thonn) plant was watched thoroughly with clean water and air-dried at room temperature for 5 weeks until a constant weight was attained, during the dry climate. It was then pulverized by rupturing the cytoplasmic cells using an industrial fine grinding machine to a particle size of $0.4 \mathrm{~mm}$ or lesser, according to the method of [26] and [27] with slight moderation. The final powdered sample was kept in an air-tight amber bottle, refrigerated for future fractionation.

\subsection{Plant extraction}

\subsubsection{Preparation of Terpenoid Rich-Fractions (TRF)}

The fraction was prepared using organic extractants [28], according to the combined methods described by [29]; [30]; [31]; and [32] with little modification as depicted in figure 2, targeting terpenoid phytoconstituents.

\subsubsection{Qualitative test for Terpenoids}

The terpenoid rich fraction $(1 \mathrm{ml})$ was added to $0.5 \mathrm{ml}$ of chloroform in a test tube, followed by a few drops of concentrated sulphuric acid. The formation of glowing reddish-brown precipitate was observed indicating the high presence of terpenoid [33].

\subsubsection{Acute lethal toxicity (LD50)}

In this study, the acute lethal toxicity (LD50) of the terpenoid concentrates was determined using up and down techniques as described by Bruce (1985) and Enegide (2013) with little modification and also conforming to the guidelines of OECD. 


\subsection{Laboratory animals}

The experiment was performed using healthy adult male Sprague-Dawley rats $(n=30)$, weighing between 150-180g, purchased from the Central Animal House, Department of Biochemistry, and housed in the primate colony of the Animal house. They were kept in wire mesh cages under a controlled light cycle (12h light/12h dark) at room temperature, fed with commercial normal rat chow (Funsab Enterprises, Agro and Livestock Raw materials Merchant, Lagos, Nigeria), ad libitum, liberally supplied with water, and acclimatized for 2 weeks before the commencement of the treatment.

\subsection{Animal grouping and Experimental design}

The animals $(n=30)$ were divided into five groups of six per set after 2-week acclimatization period, orally administered, and treated as follows early in the morning for 8 weeks [34].

Group 1: Rats on Normal chow diet

Group 2: Rats fed with high salt diet

Group 3: HSD+75mg/kg/body weight of terpenoid rich fraction

Group 4: $\mathrm{HSD}+100 \mathrm{mg} / \mathrm{kg} /$ body weight of terpenoid rich fraction

Group5: HSD+150mg/kg/ body weight of terpenoid rich fraction

The ameliorative potential of the concentrates was afterward investigated on weight and serum antioxidant status in cognizance of various biomarkers viz-a-viz MDA, GSH, Catalase, and SOD, by using standard biochemical evaluation [35].

\subsection{Feed composition}

The normal rat chow and high salt feed were bought from Funsab Enterprises, Agro, and Livestock Raw materials Merchant, Lagos, Nigeria. Below are the compositions by percentage as shown in Table 1 and 2.

\subsection{Animal Sacrificing and Dissection}

After an overnight fast post-last administration, the animals were anesthetized with chloroform vapor in a covered container for about 1 minute, sacrificed through an abdominal incision, and blood collected using $5 \mathrm{ml}$ syringes, via cardiac puncture into an ethylenediaminetetraacetic acid (EDTA) and serum bottles. With the latter standing for about 45 minutes, centrifuged at $3000 \mathrm{rpm}$ for 15 minutes at room temperature [36], the serum obtained was decanted and immediately assayed.

\subsection{Estimation of Oxidative stress and antioxidant defense system}

- Assay for Malondialdehyde (MDA) concentration 
This was estimated as described by [37], to quantify lipid peroxidation via the final product of MDA and Thiobarbituric acid (TBA), which gave a pink-colored complex that was detected spectrophotometrically at $532-535 \mathrm{~nm}$, indicating the extent of lipid peroxidation and quantification of MDA.

\section{- Reduced Glutathione (GSH) concentration determination}

The reduced glutathione (GSH) content of the serum sample, an isoenzyme/non-protein sulphurhydryls, was estimated according to the method described by [38]. To the test sample, 10\% TCA was added, centrifuged. Then $1.0 \mathrm{ml}$ of serum supernatant was treated with $0.5 \mathrm{~mL}$ of Ellmans reagent $(19.8 \mathrm{mg}$ of 5 , 5-dithiobisnitro benzoic acid (DTNB) in $100 \mathrm{~mL}$ of $0.1 \%$ sodium nitrate) and $3.0 \mathrm{~mL}$ of $0.2 \mathrm{M}$ phosphate buffer ( $\mathrm{pH}$ 8.0). The absorbance of yellowish colour developed was read at $412 \mathrm{~nm}$ which connotes the concentration of reduced glutathione in the test sample.

\section{- Catalase (CAT) activity determination}

The activity of catalase in the serum was estimated as described by [39] using a spectrophotometric kit, counting hydrogen peroxide as its main by-product.

\section{- Superoxide dismutase (SOD) activity determination}

The activity was determined by its ability to inhibit the auto-oxidation of epinephrine as described by Sun \& Zigman, 1978.

\subsection{Statistical Analysis}

The data were cross-examined using one-way analysis of variance (ANOVA) followed by Newman-Keuls Multiple Comparison Test. The significance level was set at $p<0.05(n=6)$ and the Statistical Analysis/graphing was performed using Graph Pad Prism (ver.5.0a), expressed as Mean \pm Standard deviation.

\section{Results}

In the preliminary study, the acute lethal toxicity (LD50) was determined using up and down techniques as described by [41] and [42] with little modification, and was established to be more than $5000 \mathrm{mg} / \mathrm{kg} /$ body weight. The result as shown in figure 3 further revealed a significant weight gain in rats fed with high salt diet by $54.50 \%(p<0.05)$ when compared with the animals on normal rat chow $(51.19 \%)$ after 8 weeks. The observed pathological weight gain $(p<0.05)$ is in agreement with the report of Dobrian et al., 2003, in which a proclamation of an increase in the size of adipocytes with a concomitant twofold increase in loss of leptin hormone responsiveness, and corresponding anabolism of fatty molecules via activated endoplasmic reticulum stress and phospholipase 2 [44] in salt-sensitive animal model, were reported as the metabolic etiologies. However, group orally co-treated with 75,100 and $150 \mathrm{mg} / \mathrm{kg} /$ body weight of terpenoid-rich fraction exhibited dose dependent weight recuperation potential comparatively to the control group (51.19\%). The TRF thus contains phytoconstituents that 
ameliorate obesity as also consistent with the report of by Sharma T \& Ss, (2018). The possible efficacy of the TRF of Phyllanthus amarus (Schum and Thonn) whole plant, as antiobesity in this study at various doses $(75,100,150 \mathrm{mg} / \mathrm{kg} / \mathrm{bwt})$, also agrees with the report of James et al., (2009) who also reported on the antiobesity of aqueous extract of the same plant.

Metabolic lesions driven by peroxidation of metabolic macro-molecules have been implicated in the etiopathogenesis of high salt diet related human cardiovascular diseases, eventually degrading the antioxidant integrity and thus proliferating radical cascade in high salt diet assaulted animal studies [47]. Moreover, the activities of enzymatic antioxidants viz-a-viz; SOD, CAT, and non-enzymatic antioxidant GSH had also been accounted to be compromised in another high salt related study by Juan et al. (2007). Table 3 thus revealed a significant $(p<0.05)$ increase in the level of MDA $(5.42 \pm 0.05$ vs $10.81 \pm 0.05)$ and a corresponding significant $(p<0.05)$ decrease in the activities of GSH $(62.16 \pm 0.11$ vs $41.25 \pm 0.41)$, Catalase ( $56.50 \pm 0.56$ vs $22.13 \pm 0.33)$ and SOD $(0.05 \pm 0.03$ vs $0.01 \pm 0.00)$ in groups fed with high salt diet compared to rats fed normal rat chow. The correlativity as established was in concurrence with that of Meng et al., 2003, who reported that oxidative stress influenced by high salt diet, pathologically augments MDA levels, reduce the antioxidant status, and thus contributes to hypertension with accompanying renal damage. Recuperatively, TRF revealed the ability (table 3 ) to significantly and dosedependently reduce the concentration of the oxidative marker product MDA (10.81 \pm 0.05 vs $6.03 \pm 0.18)$ to near normal group (5.42 \pm 0.05 ), with concomitant and dose-dependent metabolic improvement of non-enzymatic GSH and enzymatic catalase activity, without much significant augmentation in the activity of SOD in rats co-administered TRF and high salt diet. However, the activities of SOD initially depleted by high salt diet, regain slight stability after various administrations. The observed change is consistent with the report of Gomaa et al., 2019 who accounted for the ability of terpenoid rich extract of Elettaria cardamomum to significantly reduce Malondialdehyde (MDA) and augment the antioxidant status in animal model.

\section{Discussion}

James et al., (2009) accounted a significant decrease in the weight of animals administered with $100 \mathrm{mg} / \mathrm{kg} /$ body weight of the same plant, Phyllanthus amarus (Schum and Thonn), aqueous extract and the folkloric use of $P$. amarus as antihypertensive agent has also been noted and reported among traditional medicine practitioners, managing various diseases in Ogbomosho and its environs, via recent ethnobotanical survey, by the medicinal plant, biochemistry, and biomedical toxicology unit, Department of Biochemistry, Faculty of Basic Medical Science, College of Health Science of the university. The study thus established the safe doses of 75,100 , and $150 \mathrm{mg} / \mathrm{kg} /$ body weight of terpenoid rich constituents of the whole plant with a lethal dose more than $5000 \mathrm{mg} / \mathrm{kg} /$ body weight. The TRF also confirmed the folkloric use of the plant in the management of high salt diet-related diseases, most especially by alleviating adiposity, improving antioxidant status of catalase and Glutathione and eventually scavenging excessive MDA production. This study though validated the traditional use of Phyllanthus amarus (Schum \&Thonn), however, established the presence of terpenoid phyto-constituents, which could protect the body against high salt diet-related impairments. Withal, there is a need to isolate, identify, 
characterize, and investigate the pharmacological bases of the terpenoid rich concentrate, responsible for the activities reported.

More importantly, salt being one of the bio-essential constituents in the human diet and organs functionality, principally maintaining the electrochemical and homeostatic threshold, was also established to be deleterious and pathological, manifesting obesity and proliferation of pro-oxidant inertia, if gluttonised. While Phyllantus amarus (Schum \&Thonn) plant extract has been reported to potentiate some pharmacological activities, which include antihyperglycemic [46],

antihypercholesterolemic [22], antihypertensive [50], and diuretic potential [51], however the study further established the therapeutic ability of the terpenoid rich phyto-constituents of the plant in ameliorating high salt diet driven obesity and pro-oxidant cascade, which is non-existent in the literature. Precisely, the correlational importance of the dose-dependent ability of TRF of the whole plant, to significantly reduce high salt diet related adiposity, MDA infringement and eventually improve the antioxidant status in high salt diet-assaulted impairments in animal model, accounted within an acute period of 8 weeks were established. Hence, the medicinal plants being rich in terpenoids may be considered as a therapeutic agent in phyto-medicine, alternatively complementing orthodox health care delivery in the management of high salt diet-related human pathologies such as adiposity and pro-oxidant associated degenerative diseases.

Withal, possible mode of action and biochemical aetiologies behind this infringement as earlier accounted are: Overactive calcium influx via sodium-calcium exchanger [52]], enhancing adiposity via activation of phospholipases in response to a high $\mathrm{Na} / \mathrm{K}$ concentrating pump [53]; [54] and [55], resulting to kidney derangement in high salt-sensitive animals. Promotion of atherogenesis on the vascular intima and arterioles, resulting into vasoactive endothelial modulation (Angiotensin-converting enzymes and Endothelin converting enzyme activation but with inhibition of nitric oxide and hydrogen sulphide) and eventually compromising antioxidant integrity were also suggested [56] and [47] in another study. While Lee et al., 2016 postulated reabsorption of Sodium/Chlorine $(\mathrm{Na}+\mathrm{Cl}-)$ from the renal convoluted tubule back to the interstitium and subsequently to the lumen, resulting into hypertension derailed inotropism in another high salt related study. Nephrotoxicity, endothelial hardening, and pro-oxidant proliferation along the intima, and arterioles degradation via augmentation of lipid profile peroxidation, were also intimated by Boegehold (2013). Others include, an inflamed endoplasmic reticulum and ribosome in the cytoplasm of hepatocytes [44], activation of liver enzymes leading to fatty liver [6], decrease in antioxidant kinetics of catalase (CAT), glutathione along the mitochondrial respiratory chain, and proliferating oxidative marker product malondialdehyde (MDA) [58]; [59] were also intimated. More so, the integration of adiposity by a concomitant twofold increase in loss of leptin hormone responses [60], was also accounted by [61] and [62]. Notably, the rich terpenoid phytoconstituents from this study might have recuperated holistically, the mechanisms as highlighted above, though still subject to further research verification.

\section{Conclusions}


It was established that terpenoid rich fraction of $P$. amarus whole plant could serve as therapeutic agent in the management of high salt diet induced pro-oxidant cascade and obesity.

\section{List Of Abbreviations}

HTN- Hypertension; WHO- World Health Organization; TRF- Terpenoid rich fraction. SD- Standard deviation; HSD- High salt diet, OECD: Organization for Economic Co-operation and Development.

\section{References}

[1] H. Wiseman and B. Halliwell, "Damage to DNA by reactive oxygen and nitrogen species: Role in inflammatory disease and progression to cancer," Biochemical Journal. 1996. doi: 10.1042/bj3130017.

[2] B. T. Ashok and R. Ali, "The aging paradox: Free radical theory of aging," Experimental Gerontology. 1999. doi: 10.1016/S0531-5565(99)00005-4.

[3] E. C. Azinge, O. A. Sofola, and B. O. Silva, "Relation entre l'apport de sel, sel Goǔt de seuil et la pression artérielle chez les Nigérians," West African Journal of Medicine, 2011.

[4] M. I. Rosón et al., "High-sodium diet promotes a profibrogenic reaction in normal rat kidneys: Effects of Tempol administration," Journal of Nephrology, 2011, doi: 10.5301/JN.2010.5824.

[5] Organization World Health, "WHO | Sodium intake for adults and children," World Health Organization, 2012.

[6] M. A. Lanaspa et al., "High salt intake causes leptin resistance and obesity in mice by stimulating endogenous fructose production and metabolism," Proceedings of the National Academy of Sciences of the United States of America, 2018, doi: 10.1073/pnas.1713837115.

[7] X. chun Shen, L. Tao, W. kui Li, Y. yan Zhang, H. Luo, and Y. yi Xia, "Evidence-based antioxidant activity of the essential oil from Fructus A. zerumbet on cultured human umbilical vein endothelial cells' injury induced by ox-LDL," BMC Complementary and Alternative Medicine, 2012, doi: 10.1186/1472-688212-174.

[8] M. Ekor, "Nephrotoxicity and Nephroprotective Potential of African Medicinal Plants," in Toxicological Survey of African Medicinal Plants, 2014. doi: 10.1016/B978-0-12-800018-2.00012-1.

[9] J. P. Bertinchant et al., "Evaluation of cardiac troponin I and T levels as markers of myocardial damage in doxorubicin-induced cardiomyopathy rats, and their relationship with echocardiographic and histological findings," Clinica Chimica Acta, 2003, doi: 10.1016/S0009-8981(03)00013-5.

[10] P. Brancaccio, G. Lippi, and N. Maffulli, "Biochemical markers of muscular damage," Clinical Chemistry and Laboratory Medicine. 2010. doi: 10.1515/CCLM.2010.179. 
[11] N. D. Vaziri, X. Q. Wang, F. Oveisi, and B. Rad, "Induction of oxidative stress by glutathione depletion causes severe hypertension in normal rats," Hypertension, 2000, doi: 10.1161/01.HYP.36.1.142.

[12] A. K. Oloyo, O. A. Sofola, and M. A. Yakubu, "Orchidectomy attenuates high-salt diet-induced increases in blood pressure, renovascular resistance, and hind limb vascular dysfunction: role of testosterone," Clinical and Experimental Pharmacology and Physiology, 2016, doi: 10.1111/14401681.12595 .

[13] M. A. Bayorh, A. A. Ganafa, R. R. Socci, N. Silvestrov, and I. K. Abukhalaf, "The Role of Oxidative Stress in Salt-Induced Hypertension," American Journal of Hypertension, 2004, doi:

10.1016/j.amjhyper.2003.08.003.

[14] S. K. Jain and R. Wise, "Relationship between elevated lipid peroxides, vitamin E deficiency and hypertension in preeclampsia," Molecular and Cellular Biochemistry, 1995, doi: 10.1007/BF01076893.

[15] M. H. Yang and K. M. Schaich, "Factors affecting DNA damage caused by lipid hydroperoxides and aldehydes," Free Radical Biology and Medicine, 1996, doi: 10.1016/0891-5849(95)02039-X.

[16] P. Yang, J. O. Ebbert, Z. Sun, and R. M. Weinshilboum, "Role of the glutathione metabolic pathway in lung cancer treatment and prognosis: A review," Journal of Clinical Oncology. 2006. doi: 10.1200/JCO.2005.02.7110.

[17] G. Wang et al., "Liver Fibrosis Can Be Induced by High Salt Intake through Excess Reactive Oxygen Species (ROS) Production," Journal of Agricultural and Food Chemistry, 2016, doi: 10.1021/acs.jafc.5b05897.

[18] A. G. Kurmukov, "Phytochemistry of medicinal plants," Medicinal Plants of Central Asia: Uzbekistan and Kyrgyzstan, vol. 1, no. 6, pp. 13-14, 2013, doi: 10.1007/978-1-4614-3912-7_4.

[19] M. A. Anwar, S. S. Al Disi, and A. H. Eid, "Anti-hypertensive herbs and their mechanisms of action: Part II," Frontiers in Pharmacology, 2016, doi: 10.3389/fphar.2016.00050.

[20] B. Joseph and S. J. Raj, "An overview: Phannacognostic properties of Phyllanthus atnarus Linn," International Journal of Pharmacology, vol. 7, no. 1. pp. 40-45, 2011. doi: 10.3923/ijp.2011.40.45.

[21] G. Bagalkotkar, S. R. Sagineedu, M. S. Saad, and J. Stanslas, " Phytochemicals from Phyllanthus niruri Linn. and their pharmacological properties: a review," Journal of Pharmacy and Pharmacology, 2006, doi: 10.1211/jpp.58.12.0001.

[22] A. A. Adeneye, O. O. Amole, and A. K. Adeneye, "Hypoglycemic and hypocholesterolemic activities of the aqueous leaf and seed extract of Phyllanthus amarus in mice," Fitoterapia, 2006, doi: 10.1016/j.fitote.2006.05.030. 
[23] A. Desai et al., "Medicinal Plants and Cancer Chemoprevention," Current Drug Metabolism, 2008, doi: $10.2174 / 138920008785821657$.

[24] A. A. Adejuwon, S. M. Oluwatoyin, and A. O. Sunday, "Anti-inflammatory and Antioxidant Activities of Hunteria umbellata Seed Fractions," Pharmacologia, 2011, doi:

10.5567/pharmacologia.2011.165.171.

[25] K. Okwute Simon, C. Okolo Simon, R. Okoh-Esene, and O. Olajide Olutayo, "Biological and chemical evaluation of the extracts of the leaf of Phyllanthus amarus Schum," International Journal of ChemTech Research, 2014.

[26] S. F. Sulaiman, A. A. B. Sajak, K. L. Ooi, Supriatno, and E. M. Seow, "Effect of solvents in extracting polyphenols and antioxidants of selected raw vegetables," Journal of Food Composition and Analysis, 2011, doi: 10.1016/j.jfca.2011.01.020.

[27] S. S. Handa, S. P. S. Khanuja, G. Longo, and D. D. Rakesh, Extraction Technologies for Medicinal and Aromatic Plants. 2008. doi: 10.1021/np800144q.

[28] Z. Jiang, C. Kempinski, and J. Chappell, "Extraction and Analysis of Terpenes/Terpenoids," Current Protocols in Plant Biology, vol. 1, no. 2, pp. 345-358, 2016, doi: 10.1002/cppb.20024.

[29] M. M. Cowan, "Plant products as antimicrobial agents," Clinical Microbiology Reviews. 1999. doi: 10.1128/cmr.12.4.564.

[30] J. Azmir et al., "Techniques for extraction of bioactive compounds from plant materials: $\{A\}$ review," Journal of Food Engineering, 2013, doi: 10.1016/j.jfoodeng.2013.01.014.

[31] J.; C. Mariajancyrani G.; Brindha, P.; Saravanan, P., "GC-MS analysis of terpenes from hexane extract of Lantana camara leaves," International Journal of Advances in Pharmacy, Biology \& Chemsitry, 2014.

[32] Harwoko, S. Pramono, and A. E. Nugroho, "Triterpenoid-rich fraction of centella asiatica leaves and in vivo antihypertensive activity," International Food Research Journal, 2014.

[33] P. R. M. and Prasad M. P., "Studies on Qualitative and Quantitative Phytochemical Analysis of Cissus quadrangularis," Pelagia Research Library Advances in Applied Science Research, 2016.

[34] J. W. Gu, A. P. Bailey, W. Tan, M. Shparago, and E. Young, "Long-term high-salt diet causes hypertension and decreases renal expression of vascular endothelial growth factor in Sprague-Dawley rats," Journal of the American Society of Hypertension, 2008, doi: 10.1016/j.jash.2008.03.001.

[35] R. I. Ozolua, S. E. Idogun, and G. E. Tafamel, "Acute and sub-acute toxicological assessment of aqueous leaf extract of Bryophyllum pinnatum (Lam.) in Sprague-Dawley rats," American Journal of Pharmacology and Toxicology, vol. 5, no. 3, pp. 145-151, 2010, doi: 10.3844/ajptsp.2010.145.151. 
[36] O. E. Ofem, E. J. Ani, A. N. Archibong, and J. M. Ufford, "Variations in blood parameters of high salt loaded rats following administration of Moringa Oleifera leaf extract," Trends in Medical Research, 2015, doi: 10.3923/tmr.2015.97.105.

[37] D. Grotto et al., "Importance of the lipid peroxidation biomarkers and methodological aspects for malondialdehyde quantification," Quimica Nova. 2009. doi: 10.1590/S0100-40422009000100032.

[38] O. S. Olorunnisola, A. Adetutu, A. O. Owoade, and B. T. Adesina, "Toxicity evaluation and protective effect of Rhus longipes Engl . leaf extract in paracetamol induced oxidative stress in wister rats," vol. 6, no. 2, pp. 73-77, 2017.

[39] L. Góth, "A simple method for determination of serum catalase activity and revision of reference range," Clinica Chimica Acta, 1991, doi: 10.1016/0009-8981(91)90067-M.

[40] M. Sun and S. Zigman, "An improved spectrophotometric assay for superoxide dismutase based on epinephrine autoxidation," Analytical Biochemistry, 1978, doi: 10.1016/0003-2697(78)90010-6.

[41] E. Chinedu, D. Arome, and F. S. Ameh, "A new method for determining acute toxicity in animal models," Toxicology International, 2013, doi: 10.4103/0971-6580.121674.

[42] A. Rispin et al., "Alternative methods for the median lethal dose (LD50) test: The up-and-down procedure for acute oral toxicity," ILAR Journal, 2002, doi: 10.1093/ilar.43.4.233.

[43] A. D. Dobrian, S. D. Schriver, T. Lynch, and R. L. Prewitt, "Effect of salt on hypertension and oxidative stress in a rat model of diet-induced obesity," American Journal of Physiology - Renal Physiology, 2003, doi: 10.1152/ajprenal.00388.2002.

[44] Q. Zhang, Y. M. Yang, and G. Y. Yu, “Effects of gastrodin injection on blood pressure and vasoactive substances in treatment of old patients with refractory hypertension: A randomized controlled trial," Journal of Chinese Integrative Medicine, 2008, doi: 10.3736/jcim20080707.

[45] Sharma T and K. Ss, "Phytomolecules for Obesity and Body Weight Management," vol. 1, no. 1, pp. 1-8, 2018, doi: $10.4172 /$ jbcb.

[46] D. B. James, O. A. Owolabi, N. Elebo, S. Hassan, and L. Odemene, "Glucose tolerance test and some biochemical effect of Phyllanthus amarus aquoeus extacts on normaglycemic albino rats," African Journal of Biotechnology, 2009, doi: 10.5897/AJB09.172.

[47] P. S. Allender, J. A. Cutler, D. Follmann, F. P. Cappuccio, J. Pryer, and P. Elliott, "Dietary calcium and blood pressure: A meta-analysis of randomized clinical trials," Annals of Internal Medicine. 1996. doi: 10.7326/0003-4819-124-9-199605010-00007.

[48] S. Meng, G. W. Cason, A. W. Gannon, L. C. Racusen, and R. D. Manning, "Oxidative stress in Dahl salt-sensitive hypertension," Hypertension, 2003, doi: 10.1161/01.HYP.0000070028.99408.E8. 
A. A. Gomaa, R. M. Makboul, M. A. El-Mokhtar, E. A. Abdel-Rahman, I. A. Ahmed, and M. A. Nicola, "Terpenoid-rich Elettaria cardamomum extract prevents Alzheimer-like alterations induced in diabetic rats via inhibition of GSK3 $\beta$ activity, oxidative stress and pro-inflammatory cytokines," Cytokine, 2019, doi: 10.1016/j.cyto.2018.10.017.

[50] F. C. Amaechina and E. K. Omogbai, "Hypotensive effect of aqueous extract of the leaves of Phyllanthus amarus Schum and Thonn (Euphorbiaceae)," Acta Poloniae Pharmaceutica - Drug Research, 2007.

[51] A. N. guessan Yao et al., "The acute diuretic effect of an ethanolic fraction of Phyllanthus amarus (Euphorbiaceae) in rats involves prostaglandins," BMC Complementary and Alternative Medicine, 2018, doi: 10.1186/s12906-018-2158-0.

[52] et al Alsayed M.A., "nutrients Aqueous Fraction from Hibiscus sabdari ff a Relaxes Mesenteric Arteries of Normotensive and Hypertensive Rats through Calcium Current," 2020.

[53] M. Beg, V. Sharma, N. Akhtar, A. Gupta, and J. Mohd, "Role of antioxidants in hypertension," Journal, Indian Academy of Clinical Medicine. 2011.

[54] W. B. Farquhar, D. G. Edwards, C. T. Jurkovitz, and W. S. Weintraub, "Dietary sodium and health: More than just blood pressure," Journal of the American College of Cardiology. 2015. doi: 10.1016/j.jacc.2014.12.039.

[55] C. J. L. Murray et al., "Effectiveness and costs of interventions to lower systolic blood pressure and cholesterol: A global and regional analysis on reduction of cardiovascular-disease risk," Lancet, 2003, doi: 10.1016/S0140-6736(03)12655-4.

[56] O. A. Sofola, A. Knill, R. Hainsworth, and M. Drinkhill, "Change in endothelial function in mesenteric arteries of Sprague-Dawley rats fed a high salt diet," Journal of Physiology. 2002. doi: 10.1113/jphysiol.2002.022277.

[57] B. H. Lee, A. R. Yang, M. Y. Kim, S. McCurdy, and W. A. Boisvert, "Natural sea salt consumption confers protection against hypertension and kidney damage in Dahl salt-sensitive rats," Food and Nutrition Research, vol. 61, no. 1, pp. 1-10, 2016, doi: 10.1080/16546628.2017.1264713.

[58] D. González-Peña et al., "High-cholesterol diet enriched with onion affects endotheliumdependent relaxation and NADPH oxidase activity in mesenteric microvessels from Wistar rats," Nutrition and Metabolism, 2014, doi: 10.1186/1743-7075-11-57.

[59] R. Rodrigo, J. González, and F. Paoletto, The role of oxidative stress in the pathophysiology of hypertension. 2011. doi: 10.1038/hr.2010.264.

[60] T. L. Horvath et al., "Synaptic input organization of the melanocortin system predicts dietinduced hypothalamic reactive gliosis and obesity," Proceedings of the National Academy of Sciences of 
the United States of America, 2010, doi: 10.1073/pnas.1004282107.

[61] S. Sindhu, R. Thomas, P. Shihab, D. Sriraman, K. Behbehani, and R. Ahmad, "Obesity is a positive modulator of IL-6R and IL- 6 expression in the subcutaneous adipose tissue: Significance for metabolic inflammation," PLOS ONE, 2015, doi: 10.1371/journal.pone.0133494.

[62] M. Straczkowski, S. Dzienis-Straczkowska, A. Stêpieñ, I. Kowalska, M. Szelachowska, and I. Kinalska, "Plasma interleukin-8 concentrations are increased in obese subjects and related to fat mass and tumor necrosis factor-a system," Journal of Clinical Endocrinology and Metabolism, 2002, doi: $10.1210 /$ jc.2002-020135.

\section{Declarations}

\section{- Ethics approval and consent to participate}

The protocol of the study was approved by the Department of Biochemistry, Ladoke Akintola university of Technology review board and ethical committee, without a reference number having conformed to the International guidelines of the National Institute of Health (NIH), (publication 85-23, 1985), for laboratory animal ethics.

\section{- Consent for publication}

Not applicable

\section{- Availability of data and material}

This is to declare that all relevant data and materials as related to this investigation have been compiled within this manuscript, while any other enquiries should be forwarded to the corresponding author on reasonable request.

\section{- Competing interests}

We wish to publicly state that there is no existing conflict of interest to this study.

\section{- Funding}

The authors declare the study received no funding from any organization whatsoever.

\section{- Author contributions}

OSO supervised all the investigations, analysis, and drafting of the manuscript in agreement with AA and BSA, while TIF drafted the manuscript, surveyed and acquired the plant materials, performed extraction, rodent administration, sacrifices and all necessary biochemical evaluations. Conclusively, all authors were able to read and approve the final manuscript before submission. 


\section{- Acknowledgments}

The authors express appreciation to the technologist in charge of Biochemistry laboratory, Department of Biochemistry, School of Basic medical science, Ladoke Akintola University of Technology, Ogbomoso, Oyo State, Nigeria, for their support and technical assistance. It is also pertinent to appreciate Professor Ogunkunle A., the taxonomist, and Dr. Famuwagun I.B., those that screened and authenticated the plant and eventually preserved a sample with voucher number 0255 at the school herbarium for future reference.

\section{- Legislation for plants}

The local guideline and investigation of the plant with voucher number 0255 , were monitored, approved and authenticated by Professor Ogunkunle A., the taxonomist, and Dr. Famuwagun I.B., and eventually reserved at the school herbarium for future reference.

\section{Plant materials and authentication}

The P. amarus (Schum \& Thonn) plant was obtained fresh, locally from traditional practitioners managing various diseases in Oja Igbo metropolis, Ogbomosho, and authenticated by Dr. Famuwagun I.B., Federal University of Technology, Akure, Nigeria. The voucher sample of the plant with number 0255 was deposited at FUTA (Federal University of Technology, Akure) herbarium for a future point of reference.

\section{Tables}

Table 1: High salt diet composition 


\begin{tabular}{|c|c|}
\hline Constituents & Composition (\%) \\
\hline Corn flour & 15.00 \\
\hline Wheat offal & 9.00 \\
\hline Palm kernel cake (PKC) & 8.00 \\
\hline Soya bean meal & 5.00 \\
\hline GNC Chad & 6.00 \\
\hline Bone meal & 0.5 \\
\hline Limestone & 1.50 \\
\hline Industrial salt & 4.00 \\
\hline Lysine & 0.10 \\
\hline Methionine & 0.10 \\
\hline Grower premix & 0.15 \\
\hline Toxin binder & 0.05 \\
\hline Cibenza enzyme & 0.02 \\
\hline Vitamin C & 0.05 \\
\hline Sesame offal & 8.00 \\
\hline Powder (crushing to powder) & 19.00 \\
\hline Pelletizing \& drying size $4 \mathrm{MM}$ & 50.00 \\
\hline
\end{tabular}

Table 2: Normal rat chow composition 


\begin{tabular}{|c|c|}
\hline Constituents & Composition (\%) \\
\hline Corn flour & 15.00 \\
\hline Wheat offal & 9.00 \\
\hline Palm kernel cake (PKC) & 8.00 \\
\hline Soya bean meal & 5.00 \\
\hline GNC Chad & 6.00 \\
\hline Bone meal & 0.5 \\
\hline Limestone & 1.50 \\
\hline Industrial salt & 0.15 \\
\hline Lysine & 0.10 \\
\hline Methionine & 0.10 \\
\hline Grower premix & 0.15 \\
\hline Toxin binder & 0.05 \\
\hline Cibenza enzyme & 0.02 \\
\hline Vitamin C & 0.05 \\
\hline Sesame offal & 8.00 \\
\hline Powder (crushing to powder) & 19.00 \\
\hline Pelletizing \& drying size $4 \mathrm{MM}$ & 50.00 \\
\hline
\end{tabular}

Table 3: Effect of graded doses of terpenoid rich fraction (TRF) of Phyllanthus amarus (Schum \&Thonn) whole plant on markers of oxidative stress in rats fed with $8 \%$ high salt diet. 


\begin{tabular}{|c|c|c|c|c|}
\hline Group & MDA (nmol/ml) & GSH $(\mu \mathrm{mol} / \mathrm{l})$ & Catalase (U/mg/ protein) & $\begin{array}{l}\text { SOD U/mg/ } \\
\text { protein) }\end{array}$ \\
\hline Group1 & $5.42 \pm 0.05$ & $62.16 \pm 0.11$ & $56.50 \pm 0.56$ & $0.05 \pm 0.03$ \\
\hline Group2 & $10.81 \pm 0.05^{*}$ & $41.25 \pm 0.41 *$ & $22.13 \pm 0.33^{*}$ & $0.01 \pm 0.00$ \\
\hline Group3 & $9.38 \pm 0.22 *$ & $40.15 \pm 0.04^{*}$ & $25.22 \pm 0.01 *$ & $0.01 \pm 0.03$ \\
\hline Group4 & $7.92 \pm 0.11 *$ & $46.21 \pm 0.01 *$ & $30.31 \pm 0.05^{*}$ & $0.02 \pm 0.03$ \\
\hline Group5 & $6.03 \pm 0.18$ & $51.22 \pm 0.03 *$ & $38.52 \pm 0.03 *$ & $0.04 \pm 0.02$ \\
\hline
\end{tabular}

Data were expressed with one-way ANOVA using SPSS as mean \pm SD $(n=6)$ and considered statistically different at $\mathrm{p}<0.05$. The Data with asterisks were compared with the control group along the same column and are statistically different using Graph pad prism.

\section{Keys:}

MDA- Malondialdehyde, GSH- Reduced glutathione, CAT- Catalase, SOD- Superoxide dismutase. Group 1- Normal group

Group 2- High salt diet (HSD) fed group

Group 3- HSD+75mg/kg/bwt of PRE

Group 4- HSD+100mg/kg/bwt of PRE

Group 5- HSD+150mg/kg/bwt of PRE

\section{Figures}




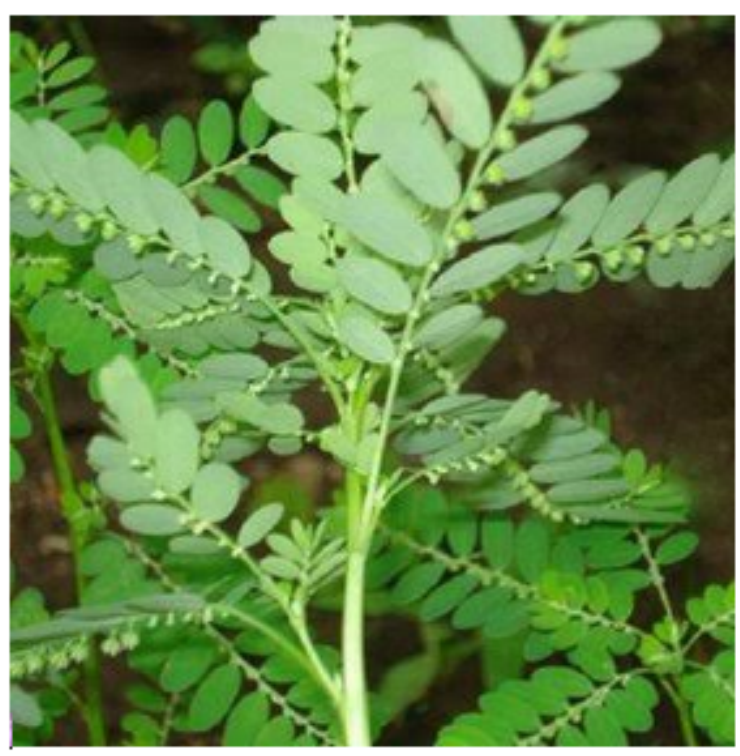

\section{Figure 1}

Phyllanthus amarus' (Schum. \& Thonn) picture taken on 29th October, 2019 at 5.20 pm, with voucher no. 0255.

\section{TERPENOID EXTRACTION CHART}

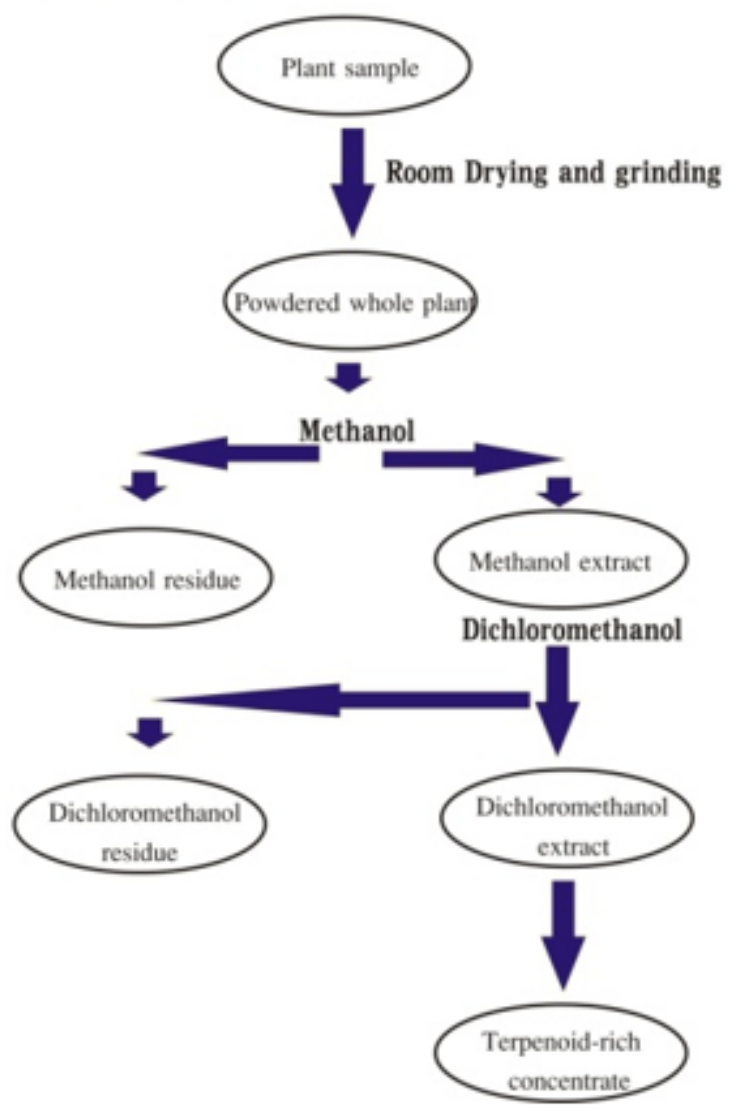

Figure 2 


\section{One way Anova data}

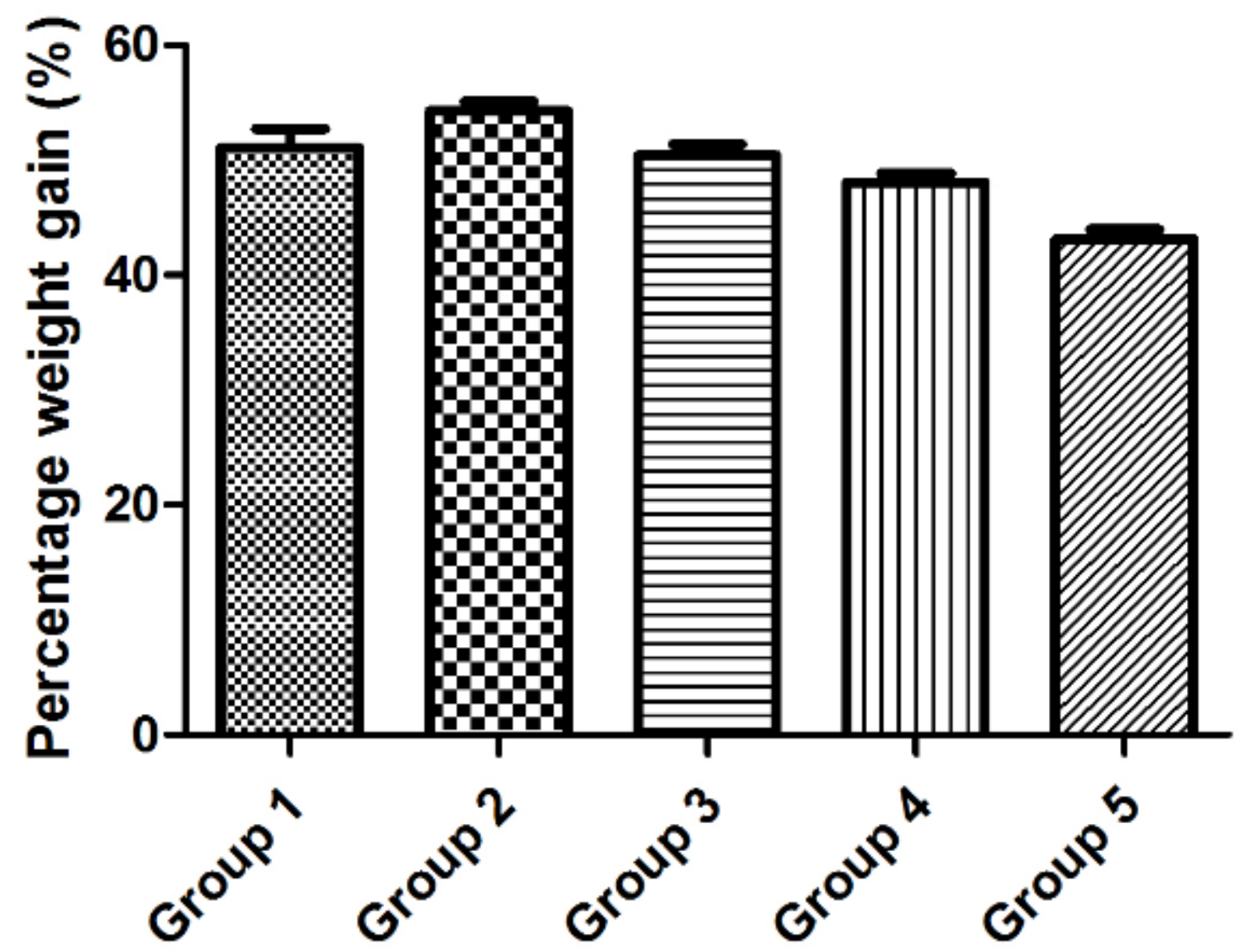

Figure 3

Effect of graded doses of terpenoid rich fraction (TRF) of Phyllanthus amarus (Schum \&Thonn) whole plant on the body weight of rats fed with $8 \%$ high salt diet.

\section{Supplementary Files}

This is a list of supplementary files associated with this preprint. Click to download.

- AuthorChecklistFull.pdf 